\title{
Does Aid Matter for Foreign Direct Investment in ECOWAS: Investigating The Infrastructure Channel?
}

\section{KENNETH ONYE}

University of Uyo

GODWIN BASSEY

University of Uyo

ALEX IRIABIJE

University of Uyo

LIONEL EFFIOM ( $\sim$ leoeff2002@yahoo.com )

University of Calabar https://orcid.org/0000-0002-1000-836X

\section{Research}

Keywords: Targeted aid, Africa Infrastructure Development Index, FDI, ECOWAS, Three Stage Least Squares.

Posted Date: January 15th, 2021

DOI: https://doi.org/10.21203/rs.3.rs-142215/v1

License: (c) (1) This work is licensed under a Creative Commons Attribution 4.0 International License. Read Full License 
Does Aid Matter for FDI in ECOWAS: Investigating the Infrastructure Channel?

\author{
By \\ Kenneth ONYE \\ Department of Economics \\ University of Uyo, Uyo \\ Nigeria \\ kennethonye@yahoo.com \\ Godwin BASSEY \\ Department of Economics \\ University of Uyo, Uyo \\ Nigeria \\ Alex IRIABIJE \\ University of Uyo, Uyo \\ Department of Economics \\ University of Uyo, Uyo \\ Nigeria \\ And \\ Lionel EFFIOM ${ }^{1}$ \\ University of Calabar, Calabar \\ leoeff2002@yahoo.com \\ (Corresponding Author)
}

${ }^{1}$ Lionel Effiom is the corresponding author. Email: leoeff2002@yahoo.com 


\section{Introduction}

The arguments on aid effectiveness have transformed over the past four decades. It has transcended "capital shortage" in the 1960s-70s to "policy failure" in the 1980s, then to "institutional failure" in the 1990s, and more recently to "infrastructure failure" in the 2000s. The studies behind these arguments have hitherto generally tried to tease out the nexus between oversees development assistance (ODA) as 'cause' and growth (or FDI, welfare, poverty) as 'effect' (see e.g. Barthel, Neumayer, Nunnenkamp and Selaya, 2014; Asiedu, Jin, and Nandwa, 2009). These studies have tended to ignore the inside of the 'cause-effect' linkage, leaving it as a 'black-box'.

But the arguments for the attractiveness of FDI over aid are typically considered compelling as it is believed to generally bring with it not only resources but technology, access to market and possible valuable training and improvement in human capital (Stiglitz, 2000). In this regard, 'aid critics' are quick to argue that successful cases of development happening as a result of large inflow of aid and technical assistant are hard to find (Easterly, 2007: 329). Yet possible complementarities between aid and FDI and potential channel through which aid could drive FDI and growth are often left in the 'black box', not least, in the context of infrastructure development in Africa.

Thus, it remains open to debate whether aid could render recipient countries more attractive to FDI. In general, the evidence from earlier studies employing aggregate aid data remains inconclusive (see e,g., Asiedu et al. 2009, Yasin 2005; Harms and Lutz 2006). The lack of consensus is partly due to the mismatch between aid instruments and development outcomes that are often used for such analysis, as well as differences in methodological approaches employed in various studies. For instance, many past studies have employed aggregate aid data (e.g., net ODA) as an instrument of development assistance and struggled to link it to the aggregate outcome (e.g., economic growth, FDI) in cross-country analysis. This approach makes it difficult to adequately unearth the link between aid and FDI as many factors unrelated to aid might drive FDI, growth, and development. Therefore, this type of approach suffers aggregation problems, much as it sometimes erroneously tries to link apple and oranges that ordinary should never be compared.

Furthermore, as most development assistance in recent times are largely delivered in form of targeted-aid, studies that try to link aggregate aid data and aggregate development outcomes miss out on sectoral and project-level information that targeted- aid studies are better equipped to incorporate in the analysis (Kotsadam, Østby, Rustad, Tollefsen, and Urdal, 2018; Findley, Powell, Strandow, and Tanner, 2011; Donaubauer, Meyer, and Nunnekamp, 2015). And as in Wayoro and Ndikumana (2018:3), targeted-aid seeks to address specific needs such as economic infrastructure project in the form of electricity, water supply and sanitation (WSS), transport, and

ICT as well as social infrastructure projects like education and health (e.g. aid for anti-malaria mosquito nets, immunization campaigns) as opposed to program aid not targeted at specific 
sectors ${ }^{2}$. We address this gap in the literature by investigating whether aid meant to improve specific elements of economic infrastructure in ECOWAS helps remove binding constraints that prevent higher FDI inflows (Hausmann, Rodrik and Velasco 2005). In order words, we examine whether aid -for-infrastructure promotes FDI through the infrastructure channel.

While poor infrastructure is known to constitute a major binding constraint to FDI inflow, the measurement of infrastructure has hitherto suffered serious data limitation rendering it difficult to provide a comprehensive evaluation of the infrastructure channel. To overcome this limitation of previous studies, we take advantage of a novel and comprehensive index of infrastructure designed by the African Development Bank (AfDB) - Africa Infrastructure Development Index (AIDI) - which is meant to help monitor the status of progress in infrastructure development across African economies.

We match these AIDI statistics with aid-for-infrastructure data retrieved from the Development Assistance Committee (DAC) dataset which is reported in the Creditor Reporting System (CRS) of the OECD database. In this way, we disaggregate aid data by focusing on aid-forinfrastructure and endeavor to link it to a unique infrastructure data set disaggregated for specific sub-sectors of infrastructure (electricity, WSS, transport, and ICT) ${ }^{3}$. We argue that the considerably improved database on various dimensions of infrastructure allows for a more systematic analysis of the link between targeted aid (aid-for infrastructure), Infrastructure outcome and FDI in the context of African economies.

Thus, this paper seeks to address two related objectives, namely to:

investigate whether aid-for-infrastructure is effective in improving the recipient country's infrastructure outcome in West Africa; and examine whether aid impacts FDI through the infrastructure channel.

Thus, we are interested in addressing the following central research question: Can carefully targeted-aid assist developing ECOWAS economies attract more FDI by removing the binding constraint associated with the infrastructure channel?

\footnotetext{
${ }^{2}$ see Wayoro and Ndikumana (2018) for recent discussions.

${ }^{3}$ To ensure that our aid-for-infrastructure data properly align one-for-one with the AfDB-designed AIDI data which is constructed from the four major components of infrastructure (transport, ICT, electricity/energy and Water Supply and Sanitation), we sum the sector-specific aid allocation to the same sectors, namely; aid for water supply and sanitation (WSS), aidfor-energy, and aid-for-transport and communication. This enables us overcome the aggregation problem that typifies many past studies on aid effectiveness and allows us to investigate more precisely the sectoral effect of targeted-aid (aid-for-infrastructure) on infrastructure outcome (AIDI) in ECOWAS.
} 
The balance of the paper is organized as follows. Section 2 gives a stylized characterization of aid-for-infrastructure, FDI, and infrastructure profile of West African economies. Section 3 provides a brief overview of the literature on the relationship between foreign aid and development outcomes. Section 4 describes the data and empirical methodology. Section 5 presents the result and 6 concludes the paper.

\section{Stylized characterization of Infrastructure outcome (AIDI), FDI, and Aid-for- Infrastructure in ECOWAS}

In this sub-section, we descriptively interrogate the data on targeted aid (aid-for-infrastructure), Infrastructure endowment/outcome (measured by the Africa Infrastructure Development Index, AIDI) and the inflow of FDI across 14 ECOWAS countries in our sample. This is with a view to gaining intuition and insights about the unconditional relationships that might exist between these variables. Considering the profile of these variables, we focus on the historical size (average), the distribution (scatter charts) and the trend characterization/evolution of aid, AIDI and FDI over the 14-year period, 2005 to 2018.

In Figure 1, we plot the horizontal-bar chart of aid-for-infrastructure, FDI and AIDI using the 14 years historical average of each of the variables. Figure 1 comprises three panels; with panel 1 and panel 2 indicating the respective charts for aid-for-infrastructure and the Africa Infrastructure Development Index (AIDI), respectively, while panel 3 shows the chart of FDI for the ECOWAS economies.

By simply eye-balling panel 1 of Figure 1, it could be easily gleaned that Ghana is by far the largest aid recipient country in ECOWAS over the 14-year period under review - with its aid-forinfrastructure amounting to an average of 180 US\$ million. This is followed by Senegal with an average of 150 US\$ million in aid-for-infrastructure. Aid-for-infrastructure is lower in countries like Burkina Faso, Benin Republic, Liberia, Mali, and Nigeria with an average aid-for-infrastructure ranging between 70-75 US\$ million. Guinea Bissau and Gambia occupied the furrow with average aid-for-infrastructure inflow of 5 US\$ and 7 US\$ million, respectively which are indeed lower than those of Guinea and Togo by few margins.

Considering the average size of AIDI, the Gambia, on the other hand, came top among sister ECOWAS countries with an average AIDI of 23.5\%. This is followed by Senegal, and then Ghana and Cote d'Ivoire. Niger Republic emerged the least Infrastructure-endowed economy in the region with an average AIDI of $4 \%$ over the 14 year period.

A perceptive look at the profile of FDI inflow across countries in the region shows that Nigeria came top in the list with an average FDI inflow of 5,850 US\$ million. This is more than double that of Nigeria's closest rival (Ghana) which has an average FDI inflow of 2400 US\$ million. As with the average size of aid-for-infrastructure, Gambia and Guinea Bissau, again, occupy the furrow (for all 
ECOWAS economies) with a paltry average FDI inflow of less than 50 US\$ million each over the entire sample period. Further, FDI inflow to Guinea and Togo surpassed those of Gambia and Guinea Bissau with some margin as is the case with aid-for-infrastructure.

Figure 1: Profile of AIDI, FDI, and Aid-for-Infrastructure in ECOWAS (2005-2018

Panel 1: Aid-for-infra (ave. 2005-18 (US\$ mil, const. pr.) Panel 2: Africa Infrastructure Developemnt Index, AIDI (ave, 05-18)
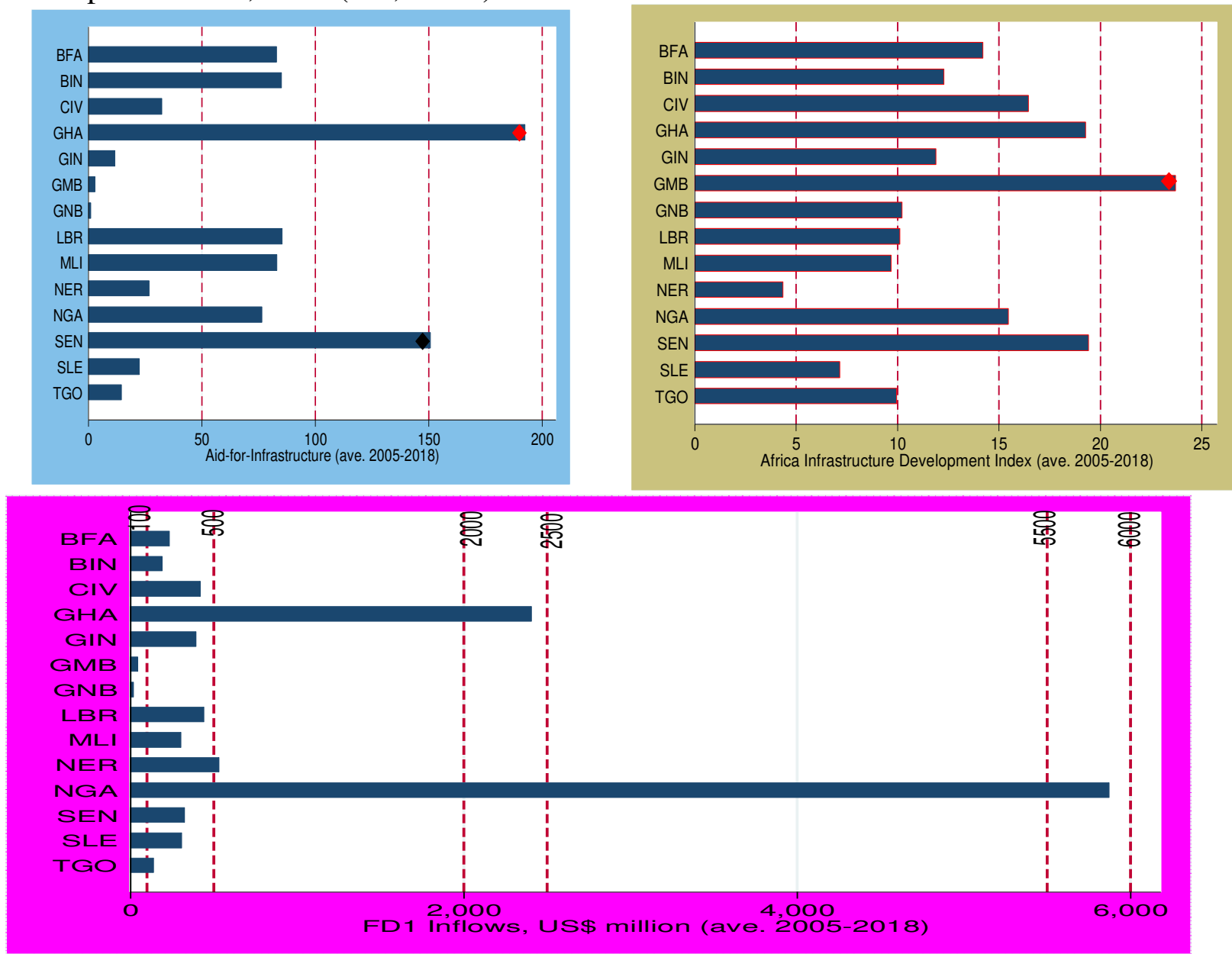

Panel 3: FDI Inflows (US\$ million, current prices)

Note: AIDI comprise of an index of WSS, index of electricity, index of Transport, and index of ICT; Correspondingly, aid-for-infrastructure is obtained as the sum of aid to 4 key components of economic infrastructure, namely; aid-to-Water supply and sanitation (WSS), aid-to-Energy, and aid-to-Transport \& communication. These four key components are carefully chosen to align with the four key components of economic infrastructure used by the AfDB in the computation of the Africa Infrastructure Development Index (AIDI), namely: WSS, electricity, Transportation, and ICT.

Overall, the general picture that emerges from Figure 1 is that a number of countries with low aid-for-infrastructure also emerged with low FDI. This is the case with countries like Gambia, Guinea Bissau, Guinea and Togo which ranked low in terms of aid-for-infrastructure as well as FDI inflow. However, the same cannot be said regarding the relative size of infrastructure outcome because these same countries did not perform abysmally poor in terms of their relative AIDI score vis-à-vis other ECOWAS countries in the sample. And so, the intuitive question that 
emerges from the trend analysis is this "what story does this aid-FDI nexus tell us particularly for countries like Gambia, Guinea Bissau, Guinea and Togo whose low aid profile also mimic their low FDI performance, considering the infra channel? We explore this more descriptively in what follows using the scatter plot/chart and, subsequently, rely on the more robust 3SLS analysis for structural interpretation.

Fig 2 shows the cross-sectional scatter chart of the variables in 2017/2018. It comprises three panels: panels A, B, and C. While Panel A shows the scatter chart of aid versus FDI, panels B and $\mathrm{C}$ indicate the scatter chart of aid versus AIDI, and FDI versus AIDI, respectively. Each scatter chart has four quadrants; Q1, Q2, Q3, and Q4 divided with reference lines. The reference lines are drawn based on the median observation for each dataset and, therefore, represent the mid-point of each axis ( $\mathrm{x}$ and $\mathrm{y}$ plane).

From quadrant 2 (Q.2) of Panel A, it could be easily seen that there is hardly any country with higher aid-for-infrastructure that performed low in terms of infrastructure outcome. In fact, there is not a single country falling into this quadrant - suggesting that higher aid-for-infrastructure is, as expected, apparently positively correlated with higher infrastructure endowment. Benin and Cote d'Ivoire typify such countries. This seems to be supported by the fact that countries like Niger, Sierra Leone, and Liberia that ranked low in terms of aid-for-infrastructure are also poor performers with respect to AIDI. Indeed, about half of the countries in our sample - namely: Nigeria, Senegal, Ghana, Burkina Faso, Mali, Guinea, Gambia - are countries with less than half of the median aid-for-infrastructure inflow and yet these countries actually surpassed the median AIDI benchmark of $15 \%$ in 2017. Intuitively, the net effect of current aid-for-infrastructure could be a function of past infrastructure endowment and other institutional factors. Consider a country where, for instance, a relatively better institution and better initial infrastructure endowment makes current aid-for-infrastructure more effective. 
Figure 2: Cross-Sectional Scatter Chart of FDI, AIDI \& aid-for-Infrastructure (2017/2018)
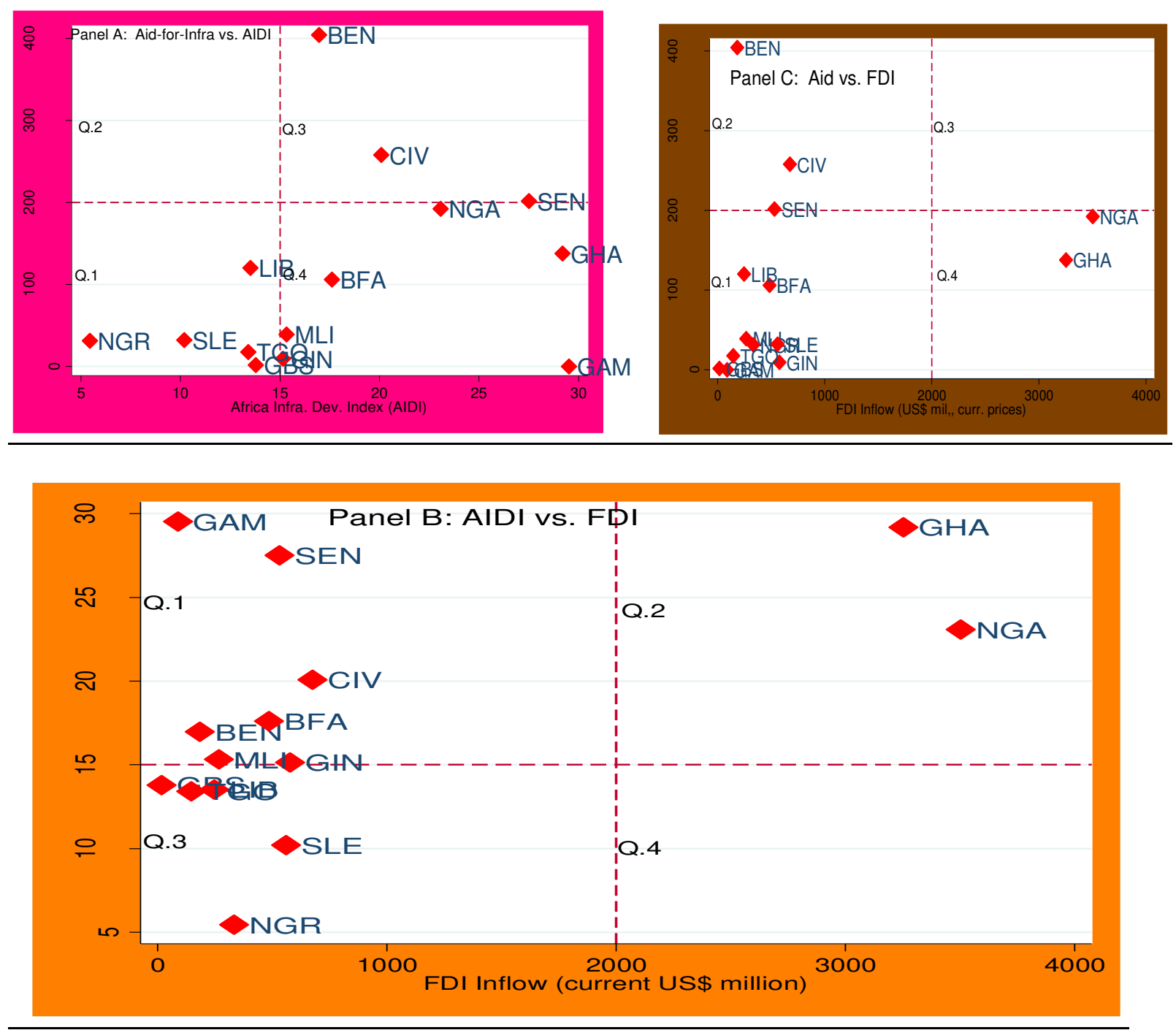

Note: (i) The reference lines (Horizontal and vertical) is based on the (estimated) median FDI and aid-for-infrastructure data for the period; (ii)Data for both FDI inflow (UNCTAD) and aid-for-infrastructure (OECD-DAC CRS) stops at 2017; (iii) Panel A is closely related to objective 1 because it shows the link between aid and infrastructure. Panel C extends the link to FDI while panel B look at the channel (infrastructure channel) and links infrastructure to FDI; (iv) Data for AIDI (AfDB, 2019) include 2018 figures) and so we use the average AIDI for 2017 and 2018.

Considering panel B and looking at the third quadrant (Q3), five countries (Niger, Sierra Leone, Togo, Guinea Bissau, and Liberia) that ranked low on AIDI also turned out to be a poor performer on the FDI scoreboard. There seems to be a counter-balance to this by the crosssectional pattern from Q1 where another set of five countries (Senegal, Cote d'Ivoire, Benin, Burkina Faso, Gambia) with higher AIDI turn turned out to be poor performers in terms of FDI inflow. While the result from two countries (Guinea and Mali) are mixed as they lie in-between Q1 and Q3, the balance of the countries, namely, Nigeria and Ghana appears to be outliers because they are the only countries with higher AIDI and higher FDI inflow. There is no country 
for which lower AIDI is associated with higher FDI. Overall, Panel B does not seem to suggest a positive nexus between infrastructure endowment and FDI inflow.

Zooming in on Panel C, however, it does seem that aid-for-infrastructure cannot easily be delinked from FDI inflow. This is because, 10 countries out of the 14 ECOWAS countries in our sample which are low aid-recipient countries turned out - to be also poor performers in the FDI scoreboard. This is the case with countries like Guinea, Gambia, Niger Republic, Togo, Guinea Bissau, Liberia, Burkina Faso, Mali, Sierra Leone, and Senegal. Surprisingly, however, the only two high aid recipient countries in 2017/18 - Benin and Cote d'Ivoire - performed poorly in terms of FDI inflow.

Overall three major pattern emerges from the cross-sectional scatter chart analysis, namely : (i) aid-for-infrastructure is apparently positively correlated with infrastructure outcome (AIDI); and (ii) there is no appreciable pattern between AIDI and FDI inflow; and (iii) aid-for-infrastructure could not easily be de-linked from FDI but appears to pass through a transmission mechanism. But as these patterns are only but a snapshot of the situation, we do not attach any structural interpretation to it. Instead, we endeavor to further probe the unconditional relationship by looking at the trend characteristics of the variables and rely on the more robust estimation technique for structural interpretations.

Figure 3: Trend Characterization of Model Variables (Super-imposed)

Figure 3 shows the graph of aid-for-infrastructure commitments (US\$ million, constant prices) scaled on the left vertical axes superimposed on the graph of infrastructure outcome, AIDI (measured from 0 -100) which is scaled on the right vertical axis. Our motivation for super-imposing the two variables is with a view to understanding more clearly the evolution of aid-for-infrastructure vis-à-vis infrastructure outcome (AIDI). 

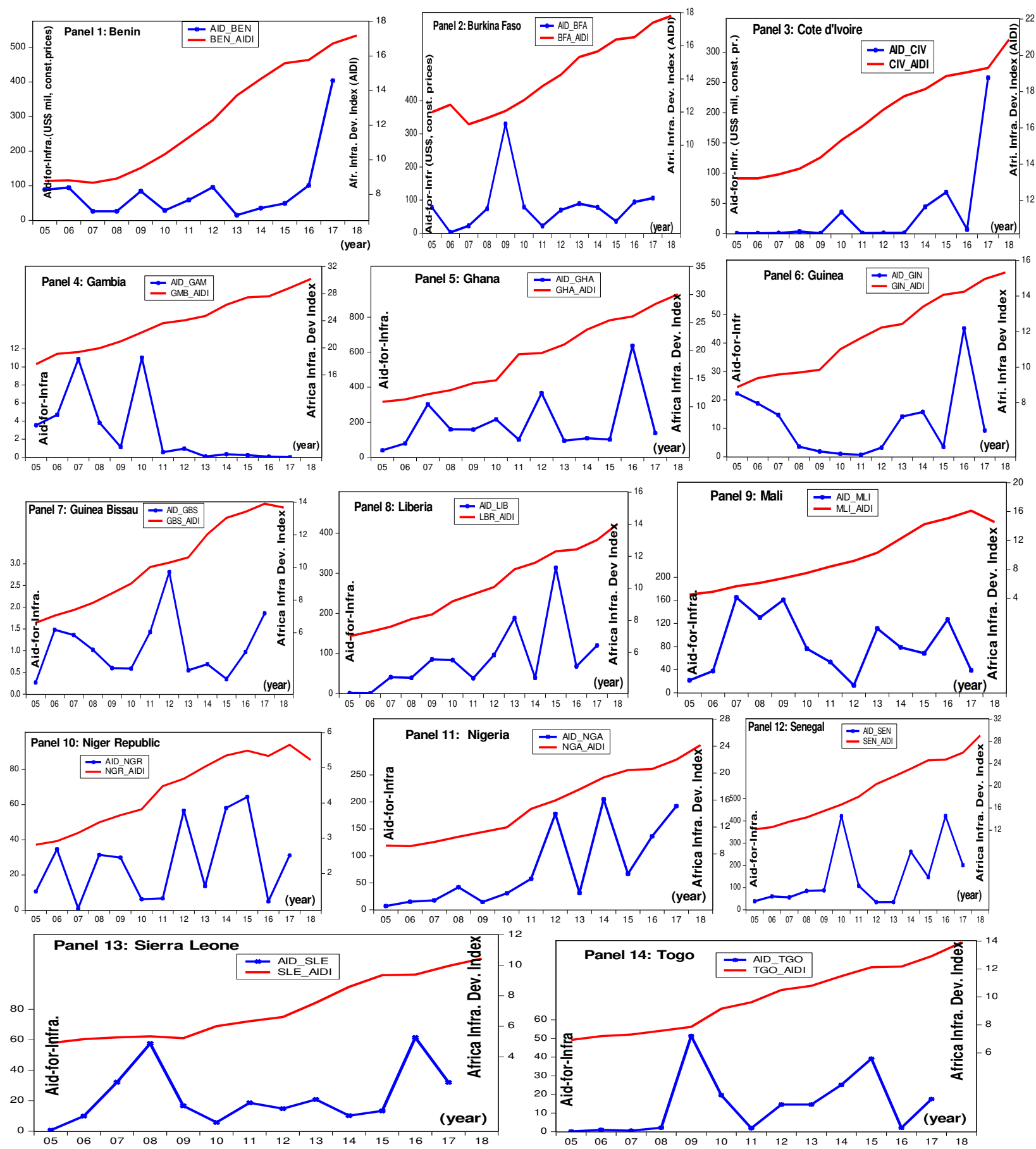

Note: (i) AIDI has a value from 0 to 100 with higher score presenting higher infrastructure endowment or outcome. However, AIDI scores for developing ECOWAS countries are generally low; it ranged from 5\% to $29.5 \%$ for our sample; (ii) Aid_Ben represents 'aid-for-infrastructure' to Benin while BEN_AIDI represents infrastructure index for Benin. For our sample, aid data ranged from \$0.3 US million to \$395 US million; (iii) The blue line (annotated with spikes) represents aid-for infrastructure and is scaled on the left vertical axis while the red line represents infrastructure endowment/outcome (AIDI) which is scaled on the right vertical axis of each panel. 


\section{The literature on aid Effectiveness and Transmission Channel}

Following the failure of many program-aid and the increasing recognition by the donor's community of the difficulties of this type of aid in inducing accelerated development, there has been a resurgence of theoretical and empirical studies focusing on how to increase aid effectiveness. Some of the mid-1990s works include Feenstra and Hanson (1997) and Aghion and Howitt (1998). On the other hand, Hoeffler and Ouram (2012) and Wayoro and Ndikumana (2018) represent recent studies in this area.

However, the avalanche of literature on aid effectiveness has been largely conducted based on macro-economic relationships between development aid as inputs and economic growth or poverty reduction as output/outcome. There are scanty studies focusing on the real insight into how aid works on ground by looking at the transmission channel through which aid ultimately impacts development outcomes (Jerve, Shimomura and Skovsted Hansen 2008; Bourguignon and Sundberg 2006). Worse still, the critical institutional factors associated with donor-recipient interactions are usually ignored or treated as a 'black-box' and the various feedback channels are poorly understood. For instance, one of the seminal works that sought to explain the East Asian Miracle (World Bank, 1993) failed to properly account for the macro- institutional interface between aid instruments and development outcomes. Hence, as Nissanke and Aryeetey (2003) note, this calls for a deeper understanding of the channels through which aid affects development outcomes.

Figure 4: Aid Effectiveness, Transmission Channels, and the Black Box

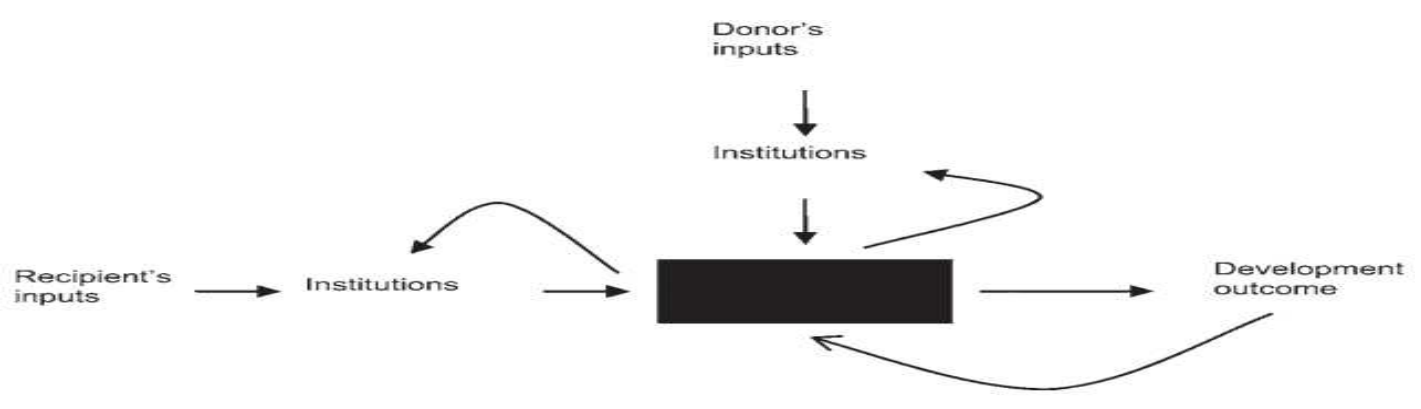

Source: Adapted from Jerve, Shimomura and Skovsted Hansen (2008:11)

The literature on aid effectiveness provides some, though typically disputed theoretical postulates on the effect of foreign aid on FDI on the one hand, and on the transmission channel through which foreign aid could impact FDI (see e.g, Donaubauer, Meyer, and Nunnekamp, 2015; Harms and Lutz 2006; Kimura and Todo, 2010). This theoretical ambiguity is not least with the empirical finding on the aid-FDI as well as aid-infrastructure linkage. 
With regard to the aid-FDI nexus, a positive effect could occur if foreign aid increases the productivity of private investment by improving the supply of complementary factors of production. In contract, foreign aid could have an adverse effect on FDI inflow by crowding out private foreign activities in the tradable goods sector or by encouraging rent-seeking activities (Beladi and Oladi, 2007; Selaya and Sunesen, 2012). In this regard, Selaya and Sunesen ( 2012) distinguished between two broad categories of aid, namely; aid-for-complementary input and aid-for-physical infrastructure. The same author finds that aid invested in complementary inputs (e.g., education, health, energy, transport, and communication) attracts FDI while aid-forphysical infrastructure crowds out FDI.

Harms and Lutz (2006) are among the most prominent empirical studies on whether aid stimulates FDI. Relying on data for 92 aid-recipient countries over the period of 1988 to 1999 , the author finds that aggregate aid per se has no significant effect on FDI inflow. In contrast, Asiedu et al. (2009) find that aid per se is negatively related to FDI in low-income host countries but that aid tends to mitigate the adverse effect of country risk on FDI. Using a panel data framework that covers the period 1990-2003 for eleven Sub-Saharan African Countries, Yasin (2005) finds a result that is in sharp contrast to that of Asiedu et al. (2009). In particular, the author finds an unconditional positive effect of aid from bilateral sources, though not from multilateral sources. However, the studies by Harms and Lutz (2006), Asiedu et al. (2009) and Yasin (2005) ignore the sector-wise composition of aid, which may help explain the highly ambiguous results.

To address this shortcoming, Meyer (2006) focused on the effect of aid-for-social infrastructure as a determinant of FDI and found a significant positive effect on FDI. Similarly, Kapfer et al (2007) found that aid targeted at economic infrastructure (which is broader than our definition of aid-for-infrastructure) positively affects FDI.

We argue that both the social infrastructure and the economic infrastructure categorization are still too broad to adequately capture specific bottlenecks to FDI that sector-specific aid may help to overcome. For instance, the OECD's economic infrastructure database not only subsumes energy, transportation. communication, essential equipment and infrastructure (e.g. road, rail, water and air transportation, television, radio and electronic information networks) but also other assistance for networks, utilities and services that facilitates economic activities, which includes, but is not exhausted by: energy: production and distribution of energy, including peaceful use of nuclear energy. Similarly, the OECD's social infrastructure data subsumes but is not exhausted by, education, educational infrastructure, services and investment in all areas, health and population, assistance to hospitals and clinics, Water Supply, Sanitation and Sewerage as well as all related assistances.

Obviously, this type of broad categorization would suffer the aggregation problem that typifies many past studies. We, therefore, rely on specific sub-categories of OECD's aid data which we call 'aid-for-infrastructure' that mimics the AfDB's sub-categories of infrastructure data used in 
the computation of the Africa Infrastructure Development Index, AIDI (see section on Data and Methodology for elaboration $)^{4}$.

There is an avalanche of literature regarding the transmission channel through which aid could potentially help to remove the bottlenecks to FDI inflow. Prominent examples, as cited in OECD (2002:34), including efforts to improve physical infrastructure, education, and health in most developing countries. Donaubauer, Meyer, and Nunnekamp (2015) analyzed aid effectiveness in FDI and notes that this type of aid may promote FDI through the infrastructure channel. But the author employed aid statistics based on OECD's classification of economic infrastructure which, as noted, is still a broader category of aid-for-infrastructure. In an earlier study, Donaubuaer et al (2014a) also analyzed aid effectiveness in education and find that aid-for-education is positively associated with FDI flows to Latin American countries. However, their empirical model failed to account for possible transmission mechanisms.

In contrast, we focus on constraints associated with a more specific component of aid statistics based on some sub-components of OECD's categorization of aid to economic infrastructure i.e., aid to energy, WSS, transport, and communication - and we thus explicitly account for infrastructure channel in our empirical model. In this way, we are able to more clearly investigate the effectiveness of aid-for-infrastructure in terms of promoting FDI in ECOWAS. In other words, we restrict the component of aid-for-infrastructure data used in our analysis to only four aid elements from the broader category of OECD's economic infrastructure, namely aid to energy, WSS, transport, and communication. Our motivation for the restriction is to allow our aid-for-infrastructure data mimic the same four components of infrastructure data used in the AfDB's computation of the AIDI index, namely; electricity, WSS, transport, and ICT.

Focusing on how improved education could serve as a transmission channel through which aidfor-education can foster FDI, the theoretical postulation of Feenstra and Hanson (1997) and that of Aghion and Howitt (1998) implies that education and worker qualification in the aid-recipient countries represents important pull factors of FDI and could equally become bottleneck were the quality is low. Insufficient education and worker qualification could discourage FDI inflows and hamper the transmission processes especially in low and middle-income countries were governance institution structures and basic physical infrastructure is in short supply.

The International Country Risk Guide (ICRG) uses a unique set of questionnaires to capture factors affecting the risk/ bottleneck to investment that is not covered by other political, economic and financial risk components. With a maximum investment climate (profile) of 12 points, a higher investment climate score represents lower risk and better opportunity for investment. We follow common practice and capture investment climate using the ICRG data on Investment Profile.

\footnotetext{
${ }^{4}$ Aid-for-infrastructure is obtained as the sum of the following sub-categories of DAC aid, namely: aid to electricity, water supply and sanitation (WSS), and transportation and communication.
} 
Our motivation for focusing on infrastructure is double folds. First, while policymakers largely agree that FDI has great potential to transfer technology and foster growth in developing countries, the challenge remains how to remove the bottlenecks that limit FDI flows - including those associated with huge infrastructure deficit in Africa (OECD 2002; UN 2003:9; Wayoro and Ndikumana, 2018). It is thus believed that addressing Africa's poor infrastructure predicament will foster FDI inflow to countries in the region. Second, the data constraint that traditionally prevented a systematic investigation of the nexus between aid, infrastructure and FDI have been relaxed with the recent release (starting from 2005) of sectoral aid data (further disaggregated by recipient developing countries) by the Development Assistance Committee (DAC) countries as reported in the Creditor Reported System (CRS) of the OECD. As noted, we match the sectoral aid data with a unique data set called Africa Infrastructure Development Index, AIDI (designed by the AfDB) which is available from 2003 to 2019. The AIDI is also available in terms of its composite indices such as electricity index, Water Supply, and Sanitation (WSS) index, transport index, and ICT index.

\section{Methodology and Data Description}

\subsection{Methodology}

We begin our empirical isometrics by abstracting from a number of specifications used in related studies (see e.g., Hoefler and Outram, 2011; Donaubauer, Meyer and Nunnekamp 2015; Jerve and Nissanke, 2008). Equation 1 represents the starting point of our empirical specification. Here we follow the standard practice to model FDI in terms of two major variables of interest, namely; aid-for-infrastructure (aid) and a measure of country-specific infrastructure endowment/outcome in Africa called the Africa Infrastructure Development Index (AIDI). We also include other traditional determinants $(\mathrm{X})$. Both aid and AIDI are included in their log forms as follows.

$$
\begin{gathered}
F D I_{i t}=\eta_{0}+\eta_{1} \log \text { aid }_{i t-1}+\eta_{2} \log \text { AIDI }_{t-1}+\eta_{3} X_{i t-1}+\gamma_{i, f d i}+\varepsilon_{i t, f d i} \\
\text { aid }=\alpha_{0}+\alpha_{1} \log \text { aid }_{i t-1}+\alpha_{2} \log \text { AIDI }_{t-1}+\alpha_{3} X_{i t-1}+\gamma_{i, \text { aid }}+\varepsilon_{i t, \text { aid }} \\
\text { AIDI }=\beta_{0}+\beta_{1} \log \text { AIDI }_{t-1}+\beta_{2} \log \text { aid }_{i t-1}+\beta_{3} X_{i t-1}+\gamma_{i, \text { inf } r}+\varepsilon_{i t, \text { inf } r}
\end{gathered}
$$

where:

aid= aid-for-infrastructure (US\$ million, constant prices); FDI = FDI inflow (US\$ million, current prices); AIDI = Africa Infrastructure Development Index (a measure of infrastructure outcome, 0-100); $\gamma_{i}=$ country fixed effect; $X_{i t}=$ set of control variables (GDP per capita, GDP growth rate, investment climate). Trade share, trade openness, and population growth rate are 
included as exclusion restriction for our sample in order to properly identify each equation of the model.

Equation 1 (FDI equation) models FDI as a function of aid and AIDI while the potential endogeneity of aid and AIDI are addressed by equations 2 and 3 respectively using the 3SLS regression technique. As has been noted, to ensure that our aid-for-infrastructure data properly align one-for-one with the AfDB-designed AIDI data which is constructed from the four major components of infrastructure (transport, ICT, electricity/energy and Water Supply and Sanitation), we sum the sector-specific aid allocation to the same sectors, namely; aid for water supply and sanitation (WSS), aid-for-energy, and aid-for-transport and communication. This enables us to overcome the aggregation problem that typifies many past studies on aid effectiveness and allows us to investigate more precisely the sectoral effect of targeted-aid (aidfor-infrastructure) on infrastructure outcome (AIDI) in ECOWAS.

The aid-for-infrastructure dataset is reported in millions of US dollars, at constant prices. Although it would have been more appropriate to use aid disbursement, we use aid commitment rather than aid disbursement because the latter is not disaggregated by countries. In other words, although aid disbursement is available for specific sub-categories (sectors) of the economic infrastructure of our interest (WSS, energy, ICT, transport), it is not disaggregated by country. The FDI data, on the other hand, are reported in millions of US dollars at current prices.

In terms of other traditional determinants of FDI, Xit in eq.1 represents the vector of control variables while $\gamma \mathrm{I}$ and $\varepsilon$ are the country fixed effects, and the error term, respectively. The entire set of control variables we consider includes GDP per capita, GDP growth rate, trade openness, and investment climate. The description of these variables and their sources are discussed in section 4.2 more completely and comprehensively. Importantly and as noted, we address the potential endogeneity of aid and infrastructure (appearing as exogenous variables in equation 1) by explicitly taking the respective determinants of aid and infrastructure into account in eq. 2 and 3 , respectively.

A rationalization of the motivation for the balance of our baseline specifications (Eqs. 2 and 3 ) is in order ${ }^{5}$. As in Hoefler and Ouram (2011), the specification of the aid-for-infrastructure model (eq.2) follows the standard literature on aid allocation literature, i.e., based on need, merit or selfinterest. Other contributions that followed this type of specification include Barthel et al (2014) and Donaubauer, Meyer and Nunnekamp (2015) In this regard, GDP per capita is commonly included as an indicator of 'general need' for aid wherein a country with lower GDP per capita would receive more aid on the basis of 'need'. And so, we consider more specific needs related to aid-for-infrastructure by introducing AIDI into the aid determinants equation (eq 2) ${ }^{6}$. Institutional variables like laws and order (from ICRG) or rule of law (from WGI) are often included to capture 'merit' because more aid could be allocated to meritorious recipients

\footnotetext{
${ }^{5}$ The seminal work on donor's self-interest is due to Alesina and Dollar (2000)

${ }^{6}$ We later modified this measure on 'need' used an approach pioneered by Donaubauer, Meyer and Nunnekamp (2015)
} 
honoring better local institutions. On the other hand, the self-interested donor is presumed to grant more aid to important trading partners proxied by trade share (in \% of total world trade). We consider population to capture the fact that more populated countries tend to receive more aid in absolute terms.

With AIDI as the dependent variable in equation 3, aid-for-infrastructure represents the explanatory variable of major interest to us in assessing whether or not aid-for-infrastructure improves the recipient countries' infrastructure outcome/endowment. Equations 1-3 are estimated simultaneously by 3SLS, which explicitly accounts for dependencies between the three structural equations $^{7}$. Our estimation period covers 2005 to 2018 for which we are able to find consistent data on three core variables of interest -AIDI, aid-for-infrastructure, and FDI.

\subsection{Data Description}

Our aid and infrastructure data comprise a panel of 14 West African countries covering a period of 2005-2017 for which we are able to find consistent data on both infrastructure-for-aid and infrastructure index, AIDI. The aid-for-infrastructure data is made up of data from the 30 Development Assistant Committee (DAC) donor countries and 14 ECOWAS recipient countries (out of a total of 186 recipient countries). Thus, like many other previous studies, our panel data set consists of directed dyads that identify a recipient-donor pair for each year (see e.g., Hoefler and Outram, 2011) ${ }^{8}$.

The data on aid is retrieved from the OECD online statistics database which provides data on DAC donor aid flows. Aid, as used in this study, refers to ODA which is generally defined as official financing administered with the main objective of promoting development and welfare of recipient countries. ODA defined in this way must be concessional in character with a grant element of at least $25 \%$ (using a fixed $10 \%$ rate of discount) (OECD, 2019). Defined as ODA, aid includes technical assistance but excludes military assistance whether in form of credit, loan or grants as well as transfers to individuals.

As is conventional in the aid studies literature, we use aid commitment rather than disbursement, which would provide a more accurate intended aid allocation by donors in a given year. It would have been more appropriate to used disbursement data. However, this is not available on a consistent basis by country.

\footnotetext{
${ }^{7}$ As in Donaubuaer et al (2015:10), trade share, openness and population are included as exclusion restriction for our sample in order to ensure that each equation of the system is properly identified

${ }^{8}$ We include only Official Development Assistance (ODA) to part I countries -leaving out other Official Flows (OOF) and Other Aid (OA) because our focus is on aid meant for development purpose. The OOFs are aids which are not classified as ODA because they are either not meant for development purpose or they have a grant element of less than $25 \%$, if they are loans. OAs are aids which meet the condition of ODA except that the recipient country belongs to part II of the DAC classification of aid recipient countries. For aid to qualify as ODA, it must have 3 key features, namely, it must: (i) be undertaking by the official sector/agency (e.g., central, state and local government; (ii) have as its main objective to promote economic development and welfare (hence the term development aid); and (iii) if loan, it must have at least $25 \%$ grant element. These features are used to distinguish ODA from the other two categories of aid such as the OOF and OA. Since 2005, the OECD has abolished the definition of part II countries and has reverted to a sigle list of recipient countries.
} 
To ensure that our aid-for-infrastructure data properly align one-for-one with the AfDB-designed AIDI dataset which is constructed from the four major components of infrastructure (transport, ICT, electricity/energy and Water Supply and Sanitation), we sum the sector-specific aid allocation to the same sectors, namely; aid for water supply and sanitation (WSS), aid-forenergy, and aid-for-transport and communication. This constitutes an important value addition that enabled us overcome the aggregation problem that typifies many past studies on aid effectiveness and allows us to investigate more precisely the sectoral effect of targeted-aid (aidfor-infrastructure) on infrastructure outcome (AIDI) in ECOWAS.

\section{Results}

The discussion of result covers three major sub-sections, (a) through (c). A discussion of the baseline result is presented in ' $a$ '. Following our finding of weak evidence for a need-based allocation of aid in the baseline result, we follow a standard approach and derive the 'need' related to infrastructure from the 'potential' AIDI dataset retrieved via the HP filter (see subsection b). Finally, to check the robustness of our regression to alternative measures and definitions of FDI (the ultimate variable in the 3SLS model), we report the result of the robustness checks in 'c' (see also Table 3 in Appendix A)

\section{(a) Baseline 3SLS Regression Result}

Table 1 reports the result of the baseline estimation of equations 1 to 3 earlier presented in section 4 .

Table 1: Baseline 3SLS Regression Estimate

\begin{tabular}{|c|c|c|c|}
\hline & 1 & 2 & 3 \\
\hline Variables & FDI Flow & Aid & Infrastructure (AIDI) \\
\hline Log Aid-for-Infrastructure (Aid) & $\begin{array}{l}0.16 * * \\
(0.025)\end{array}$ & & $\begin{array}{l}0.008 * * \\
(0.023)\end{array}$ \\
\hline Infrastructure (AIDI) & $\begin{array}{l}-0.68 * * \\
(0.001)\end{array}$ & $\begin{array}{c}-0.00067 \\
(0.9)\end{array}$ & \\
\hline Log GDP per capita (logGDPC) & $\frac{3.45 * *}{(0.005)}$ & $\frac{1.24 * * *}{(0.0001)}$ & $\frac{0.04 *}{(0.06)}$ \\
\hline Log Real GDP (logRGDP) & $\begin{array}{c}-3.13 \\
(0.006) *\end{array}$ & & \\
\hline GDP growth Rate (GDPG) & $\begin{array}{r}-0.024 \\
(0.17)\end{array}$ & & \\
\hline Investment Climate (iclimate) & $\begin{array}{c}0.11 \\
(0.15)\end{array}$ & $\begin{array}{c}0.32 * * * \\
(\mathbf{0 . 0 0 6})\end{array}$ & $\begin{array}{l}0.11 * * * \\
(0.0001)\end{array}$ \\
\hline Law \& Order (law) & $\begin{array}{c}-\mathbf{0 . 1 2} * * * * \\
(0.004)\end{array}$ & $\begin{array}{c}0.25 * * * \\
(0.001)\end{array}$ & $\begin{array}{r}-0.09 * * * * \\
(0.0001)\end{array}$ \\
\hline Log trade Openness $(\log \mathrm{OPN})$ & $\begin{array}{l}0.6 * * * * \\
(0.001)\end{array}$ & & \\
\hline trade Share (tshare) & & $\begin{array}{l}-7.9 * * * \\
(0.0001)\end{array}$ & \\
\hline Population Growth Rate (popu) & & & $\begin{array}{c}-0.27 * * * \\
(0.001)\end{array}$ \\
\hline Constant & $\begin{array}{l}-7.1^{*} \\
(0.08)\end{array}$ & $\begin{array}{c}-29.8^{* * * *} \\
(0.001)\end{array}$ & $\begin{array}{l}1.8 * * * * \\
(0.004)\end{array}$ \\
\hline Observations & 138 & 138 & 138 \\
\hline
\end{tabular}


$\begin{array}{llll}\text { R-squared } & 0.78 & 0.44 & \mathbf{0 . 4 1}\end{array}$

Source: Stata Output: Note: Probability values are reported in parenthesis. ${ }^{* * *} \mathrm{p}<0.01 ;{ }^{* *} \mathrm{p}<0.05 ;{ }^{*} \mathrm{p}<0.1$. All explanatory variables are lagged by one year following standard practice.

By focusing on column 3 which shows the result of the equation 3 in which infrastructure is the dependent variable, we found fairly strong and robust evidence that richer countries (with higher GDP per capita) tend to be better endowed with higher level of infrastructure ${ }^{9}$. Our result also shows that ECOWAS countries with lower population growth rate and those with better investment climate (ICRG) appear to be more significantly endowed with higher level of infrastructure. Considering the face value of our coefficients, equation 3 shows that a 10 percent increase in GDP per Capita is associated with a highly significant increase in infrastructure by 0.4 points on the $0-100$ scale of the Africa Infrastructure Development Index (AIDI). Similarly, a 10 percent improvement in investment climate (on the 0-12scale) would lead to a statistically significant increase in infrastructure endowment by 1.1 on the AIDI scale ${ }^{10}$. On the other hand, a 10 percent rise in population growth rate would significantly decline infrastructure endowment in ECOWAS by 2.7 points on the $0-100$ scale of the AIDI.

The most interesting finding from eq 3 is that aid-for-infrastructure appears to be effective in improving the recipient countries' endowment with economic infrastructure. Indeed, the coefficient of aid-for-infrastructure proved to be statistically significant at the one percent level.

Turning to the determinants of aid allocation and taking a perceptive look at the allocation based on 'need', 'merit' or 'self-interest', some interesting results emerge. In particular, our specific indicators of need - namely AIDI turned out to be negative (as expected) - suggesting that more aid-for-infrastructure is allocated to countries with lower (initial) infrastructure endowment although this is not significant. However, the commonly used measure of general 'need' - i.e., GDP per capita - proved to be positive against theoretical a priori expectation. A possible explanation of the positive sign is that the aid data we used refers to the more specific (and targeted) aid-for-infrastructure rather than aggregated aid that covers general need. In this regard, it is noteworthy that GDP per capita is commonly used to capture 'general need' related to such aggregated aid data. And so, the positive sign of GDP per capita would not be too surprising after all.

Thus, eq 2 tends to suggest that for the specific case of aid-for-infrastructure, an important consideration by DAC donor countries could have been the initial level of infrastructure endowment (rather than the more general need that relates to GDP per capita). Yet, although negative as expected, aid allocation on the basis of previous infrastructure endowment has been insignificant as the usual 5\% level. Therefore, taking the result of eq 3 and eq 2 together, our findings reveal that aid-for-infrastructure is effective in improving infrastructure endowment in

\footnotetext{
${ }^{9}$ see Donaubauer, Meyer and Nunnekamp (2015); Jerve and Nissanke (2008), Vigile and Wagner 2012 for similar result).

${ }^{10}$ The higher the iclimate score (on the 0-12 scale), the lower the risk associated with investment. Similarly, the higher the 'law \& order' score (on the 0-6 scale), the better is compliance associated with law and order.
} 
ECOWAS but this has not been sufficiently focused on countries where initial infrastructure endowment is lowest/minimal.

Importantly, eq 2 also suggests that the allocation of aid-for-infrastructure is strongly influenced by the recipient countries' 'merit' for aid as indicated by 'law and order'. The significantly positive effect of law and order suggests that donors appear to consider recipient countries' compliance with law and order in the allocation of aid-for-infrastructure. Looking at the size of the coefficient of 'law and order', it is easily seen that a one percent improvement in terms of compliance with (ICRG) law and order (on the 0-6 scale) is associated with 0.25 percent increase in aid allocation. However, the role of donors' economic or strategic self-interest as reflected in trade share seems to have received a rather trivial consideration in the specific case of allocation of aid-for-infrastructure in ECOWAS. From eq 2, therefore, we found that the most important determinant of aid allocation in ECOWAS countries is 'merit', followed by weak evidence for aid allocation based on 'need'.

Therefore, our finding of a combination of a positive (and significant) effect of aid-forinfrastructure on infrastructure endowment (eq.3), and our finding of a meritorious aid-forinfrastructure allocation (indicated by a significantly positive coefficient of law and order in eq.2) suggests as follows. (i) aid-for-infrastructure is effective in improving infrastructure outcomes in ECOWAS, and (ii) DAC aid allocation has primarily been made on the basis of 'merit', and to a weaker extent, the recipient countries 'need' for aid.

Turning to the FDI equation (eq.1), we reiterate that the endogeneity of 'aid-for-infrastructure' and AIDI as our major determinants (of interest) in the FDI equation is accounted for by the 3SLS regression model. In general, we found some plausible results regarding the coefficients of the control variables included in the FDI equation. For instance, the significant positive coefficient of GDP per capita in the host ECOWAS Countries implies that rising income in these countries is associated with the higher inflow of FDI. The quantitative size of the GDP per capita is also large; it indicates that a one percent increase in GDP per capita is associated with a 3.45 increase in FDI inflow. Higher GDP and GDP growth cannot be easily linked with higher FDI inflows. This might be expected for a developing region like ECOWAS where investment climate and ease of doing business have been a key consideration by foreign investors. In this regard as expected, FDI inflow is found to be positively associated with investment climate. In fact, we found this positive relation to hold for all three specifications. And for equations 2 and 3 , in particular, investment climate is highly statistically significant at 1 percent level. As expected, trade openness is found to be positively related to FDI with an elastic impact of 0.6.

Considering the channel through which aid impacts FDI, the index of infrastructure has a surprisingly negative effect on FDI. In contrast, aid-for-infrastructure has a statistically significant positive effect on FDI. The later suggests that aid-for-infrastructure could have a direct effect on FDI inflow. The quantitative impact of aid-for-infrastructure on FDI is nontrivial. The elastic coefficient is 0.16 . We do not find evidence from the study that aid-for- 
infrastructure improves FDI inflow through the infrastructure channel. To be clear, we make no claim that the effect of aid-for-infrastructure on FDI does not pass through any transmission mechanism. What our result clearly shows is that there is no clear evidence that the positive effect of aid-for-infrastructure on FDI inflow necessarily passes through the infrastructure channel. Interestingly, a possible explanation for the apparent positive and direct effect of aidfor-infrastructure on FDI is that foreigners tend to invest in anticipation of improvement in infrastructure endowment that aid targeted as specific sub-sectors of economic infrastructure almost always tend to bring.

\section{(b) Modified Infrastructure Need}

Following our earlier finding of weak evidence for a need-based allocation of aid in the baseline result, we modify the measurement of the recipient countries' 'need' for aid-for-infrastructure following recent approach. We define the concept 'infrastructure need' - i.e., the need for infrastructure that could also create need for aid-for-infrastructure - as the difference between a measure of the normal or long-run pattern of AIDI and the actual AIDI. In particularly, we define infrastructure need as "long run (potential) AIDI less actual AIDI". Apparently, this definition is conceptually the opposite of our notion of 'gap' which is generally measured as actual value of a variable less its potential value ${ }^{11}$. In a related approach, Donaubauer, Meyer, and Nunnekamp (2015) measured 'infrastructure need' as all positive values obtained from subtracting actual Infrastructure index from expected/predicted infrastructure index.

However, we differ from the same author in two major ways, namely: (i) rather than rely on predicted/expected infrastructure index to calculate 'infrastructure need', we rely on the potential infrastructure index retrieved via the HP filter. As we shall soon see, we found that the measure of 'need' based on potential AIDI provides a more robust coefficient of 'infrastructure need' in the regression model; and (ii) In contrast to this author too, we do not assume that the negative values of the 'infrastructure need' dataset that we obtain imply zero 'need'. Instead, we interpret the negative values to imply the 'true' shortfall in the level of infrastructure, i.e., the so-called 'infrastructure deficit or gap'. In this way, therefore, we follow the standard measure of gap in economics literature.

Nonetheless, in fellowship with the same author, we carefully avoid the use of 'infrastructure gap' dataset for our estimation ${ }^{12}$. An important advantage of the use of 'infrastructure need' data over 'infrastructure gap' data is that it makes for a straightforward interpretation of our coefficient of 'infrastructure need' in the 'aid' equation. More precisely, as higher 'need' should

\footnotetext{
${ }^{11}$ For instance, GDP gap is defined as actual GDP less potential GDP. In this sense inflationary gap is the amount by which by which the actual GDP exceeds potential full-employment GDP

12 However, this is operationally equivalent to assuming that the negative value of 'infrastructure need' dataset implies zero 'need' since the log of zero dataset are also undefined. But the distinction is important where the data are included in their level form rather than in their natural log form into the regression model.
} 
attract higher aid from donors, 'infrastructure need' is expected to be positively related to aidfor-infrastructure.

Table 2 (Appendix A) reports the 3SLS result of regression using the modified measurement of 'need'. As can be seen, while we now find evidence of need-based aid allocation from Table 2, there is slight decline in the statistical significance and size of the regression coefficients compared to the baseline estimates (Table 1). In particular, while aid-for-infrastructure continued to exact a positive effect on the recipient countries' infrastructure endowment, it does so at a lesser significance level and with lower quantitative impact.

Zooming in on the determinants of aid allocation (eq2), the introduction of the modified need changes the picture as noted. From equation 2 of Table 2, we now found evidence of need-based allocation of aid. The coefficient of infrastructure need is positive (as expected) and significant at the $10 \%$ level. The quantitative impact is 0.24 . Taking at face value, this implies that a 10 percent rise in infrastructure need is associated with 2.4 percent increase in aid-for-infrastructure. Per capita GDP continued to maintain its surprising positive sign which, as noted, could be so because the aid data we used refers to the more specific aid-for-infrastructure rather than aggregated aid that covers the general need. Conversely, the coefficient of investment climate is positive (as expected) and highly significant with an elastic impact of 0.52 . This suggests that ECOWAS countries with better investment climate (ICRG) appear to receive more aid for investment in infrastructure.

The indicator of aid allocation by merit (law and order) continued to maintain a positive effect, although at a lesser significance level. As earlier noted, the positive effect of law and order suggests that DAC donors apparently consider recipient countries' compliance with law and order in the allocation of aid-for-infrastructure. In other words, DAC aid allocation could be considered meritorious. Also as noted, the role of donors' economic or strategic self-interest as reflected in trade share continued to receive a trivial consideration in the specific case of allocation of aid-for-infrastructure in ECOWAS. A possible explanation is that the aid data that we considered is, ab initio, targeted aid, i.e., aid targeted at specific sub-categories of economic infrastructure as opposed to other aid (for sectors other than infrastructure).

Turning to the channel through which aid impact FDI, the introduction of the modified need did not, however, change the picture so much. Infrastructure continued to maintain a surprising trivial effect on FDI inflow. By contrast, aid-for-infrastructure maintained a strong and statistically significant positive effect on FDI with an elastic impact of 0.01 . This finding suggests that aid-for-infrastructure exerts a direct (nock-on) effect on FDI inflow.

GDP per capita continued to maintain a positive effect on FDI implying that rising per capita income in recipient ECOWAS economies is associated with the greater inflow of FDI. The quantitative size of GDP per capita is also large at 4.8. As with the baseline result, higher GDP and GDP growth rates are not associated with greater FDI inflow. By contrast, trade openness - 
as expected - is found to be positively associated with higher FDI inflows. And this is found to be highly significant with an elastic impact of 0.6 .

\section{(c) Robustness Checks}

In implementing the robustness checks, we continue to use the modified measurement of 'need' specifically related to infrastructure. Markedly, we reiterate that infrastructure and aid-forinfrastructure are our two major variables of interest in the FDI equation. But while aid-forinfrastructure flows should fit well with FDI flow that we have hitherto used in the preceding regression results discussed, FDI stock may provide a better fit with the persistent endowment of infrastructure stock in ECOWAS economies. Therefore, we test the robustness of the regression results to the alternative definitions and measurements of FDI (our ultimate dependent variable in the 3SLS regression model). In particular, we test if there is a detectable change in the size and significance of our coefficients when FDI flow is replaced with FDI stock. We extend the robustness checks to estimates where FDI is now measured in percent GDP rather than in US\$ (unreported).

From the robustness checks conducted, the key results are as follows. First, the coefficient of modified 'need' remains positive to alternative definitions and measurement of FDI. Second, overall results are robust to - (i) alternative measures of FDI (FDI Flow \& FDI stock); and (ii) alternative definition of FDI (e.g., FDI flow in \% GDP, FDI stock in \% GDP, FDI flow in millions of current US\$, FDI stock in in millions of current US\$,). And third, using predicted AIDI (rather than potential AIDI) to calculate 'infrastructure need' produced coefficients of 'need' that are not robust to alternative measures of FDI as it switches sign depending on whether FDI stock or flow is used.

Table 3 (Appendix A) reports the result of the robustness check after re-estimating the model (reported in Table 2) with FDI stock as the ultimate dependent variable. From Column 3 of Table 3 , the evidence on the determinants of the ECOWAS countries' endowment with infrastructure is basically the same as the corresponding column 3 of Table 2, qualitatively and quantitatively. For both Table 3 and 2, there was general decline in the size and significance of the coefficients following the introduction of modified 'need' when compared with Table 1. In this regard, aidfor-infrastructure continued to exert a positive effect on infrastructure endowment in ECOWAS. As noted, the significance and quantitative size of the coefficient remain the same for Tables 2 and 3 but declined with respect to the baseline estimate.

Looking at eq 2 of Table 3, the allocation of aid continued to be need-based when FDI stock is used to replace FDI flow in the model. As can be seen from column 2 of Tables 3 and 2, the quantitative impact when FDI flow is used is 0.24 and this is statistically significant with a probability value of 0.007 . With FDI stock, the quantitative impact rose slightly to 0.26 and the statistical significance increased as the probability value now turns out to be 0.049 . 
Focusing on the determinant of FDI and paying particular attention to our major variables of interest, we, again, did not find evidence that aid-for-infrastructure does impact FDI indirectly through the infrastructure channel. If anything, the result shows that aid-for-infrastructure continues to exert a positive and direct effect on FDI inflow. As with the general decline in the size and significance of the coefficients when modified 'need' is used, aid-for-infrastructure turns out to be less significant.

Overall, the result of the robustness check provides clear evidence that the coefficient of the variable - including 'infrastructure need' remains basically the same quantitatively and qualitatively - irrespective of the FDI definition (stock or flow) used in the 3SLS regression. We also find the coefficients to be robust to alternative measurements of FDI, i.e., either in \%GDP or US\$ (available on demand).

\section{Conclusions \& Policy Insights}

The poor attractiveness of developing ECOWAS economies to FDI seems to have become intractable over the past decades. This problem appears to have become compounded in recent times in view of emerging 'Donor Fatigue' across development partners and donor organizations worldwide. Can the OECD's (2003: 33) claim that “... a carefully targeted development assistant could assist in leveraging FDI..." relate well to social and economic infrastructure in ECOWAS? In this paper, we test the hypothesis that aid targeted at specific sub-categories of economic infrastructure helps developing countries attract higher FDI inflows through improvement in their infrastructure endowment in Water Supply and Sanitation (WSS), Energy, Transportation, and ICT.

We make use of a comprehensive index of infrastructure (Africa Infrastructure Development Index, AIDI) designed by the African Development Bank (AfDB). And we cover 14 ECOWAS countries for the period 2005-2018, for which consistent data are available. By relying on the 3SLS regression, we explicitly account for potential endogeneity between three structural equations on the determinants of sectoral aid, the determinants of FDI and the determinants of infrastructure. Our approach, as with past studies, permits a simultaneous assessment of three critical junctures in the transmission from aid to FDI. These include: (i) whether or not aid is effective in improving the recipient country's infrastructure; (ii) whether or not the allocation of aid is need-based by targeting countries with minimal infrastructure endowment; and (iii) whether or not aid impact FDI via infrastructure channel.

As noted, we affirm our major research question that carefully targeted aid (aid-forinfrastructure) helps ECOWAS countries attract more FDI but not without a caveat. Although aid-for-infrastructure shows robust positive effect on infrastructure and on FDI, its impact on the latter is not necessarily via infrastructure channel as investors apparently anticipate the longerterm effects of aid on the country's infrastructure endowment and expect aid-financed infrastructure to serve them particularly well. 
In other words, we found no evidence that the positive effect of aid on FDI passes through the infrastructure channel. Instead and if anything, we find fairly strong and robust evidence that aid exerts a direct knock-on effect on FDI. And as has been noted, this is apparently because foreigners invest in anticipation of the positive effect that aid targeted at infrastructure is almost always inclined to produce on host countries' infrastructure endowment. To be clear, we make no claim that the positive effect of aid on FDI does not transcend any transmission channel. Instead, what our result clearly shows is that contrary to common belief, aid targeted on infrastructure does impact FDI but not necessarily through the infrastructure channel. To conclude, while there is strong evidence of merit-based 'aid-for-infrastructure' allocation by DAC Donors, we found that this has not been sufficiently focused on ECOWAS countries where initial infrastructure endowment is minimal.

\section{Lessons for Policy and Prospects for Research}

(i)Given that 'meritorious aid' indicates the strongest evidence on what determines aid allocation in ECOWAS and that allocation have yet to sufficiently focus on countries where initial infrastructure endowment in minimal, making developing countries more attractive to FDI will, therefore, entail more emphasis on countries with lower initial infrastructure endowment.

(ii) In view of the positive effect of 'aid-for-infrastructure' on infrastructure outcome and FDI, coupled with our finding of need-based aid allocation, donors can make aid promote higher FDI by also focusing more on need-based aid allocation.

(iii). Given the robustness of the modified 'infrastructure need' (based on Potential AIDI) to alternative definitions of FDI (flow, stock) and alternative measurements of FDI (\%GDP, US\$), extended research effort at index construction and data collection is important. This could prove useful to identify country-specific transmission channels from aid to FDI and, hence, the binding constraints to higher FDI inflows in economic infrastructure. This could also show whether the corresponding aid category are effective in overcoming such binding constraint to FDI inflow

\section{Declarations}

\section{Acknowledgments}

Our sincere thanks go to the prospective reviewers and editors of this paper. Their services would no doubt improve the quality of this paper greatly.

\section{Authors' Contributions}

Kenneth ONYE and Godwin BASSEY conceptualized the study and wrote the introduction as well conducted the analysis, while Alex IRIABIJE and Lionel EFFIOM sourced for the data, wrote 
the literature review and conducted the general editorial corrections. All authors proofread and approved the manuscript submission

\section{Funding}

This study had no funding whatsoever

\section{Availability of data and materials}

This study's data were sourced from African Development Bank (AfDB) and OECD databases.

\section{Competing Interests}

I hereby declare the absence of existing or potential conflicting interests for this study 

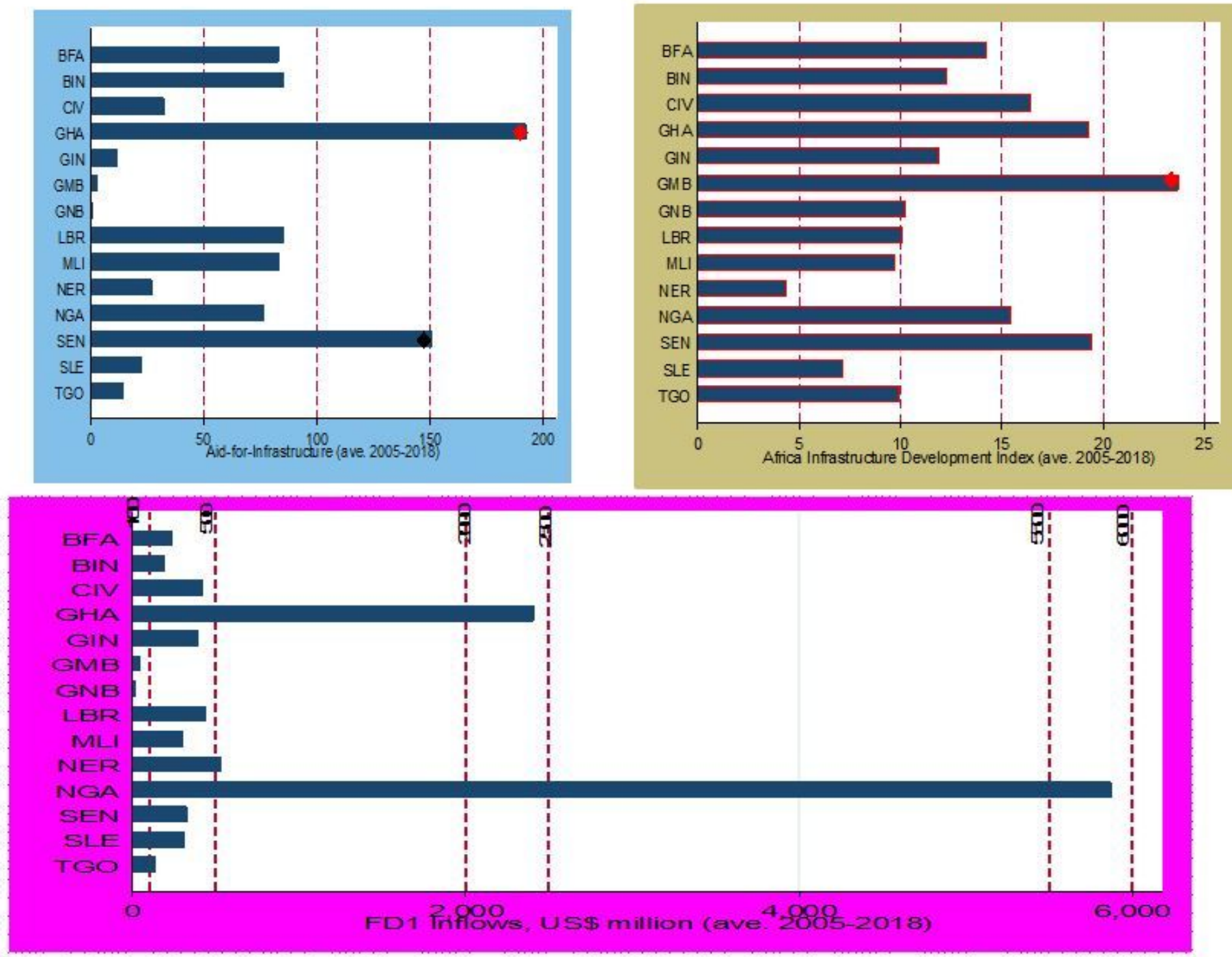

\section{Figure 1}

Profile of AIDI, FDI, and Aid-for-Infrastructure in ECOWAS (2005-2018 Panel 1: Aid-for-infra (ave. 2005-18 (US\$ mil, const. pr.) Panel 2: Africa Infrastructure Developemnt Index, AIDI (ave, 05-18) Panel 3: FDI Inflows (US\$ million, current prices) Note: AIDI comprise of an index of WSS, index of electricity, index of Transport, and index of ICT; Correspondingly, aid-for-infrastructure is obtained as the sum of aid to 4 key components of economic infrastructure, namely; aid-to-Water supply and sanitation (WSS), aid-to-Energy, and aid-to-Transport \& communication. These four key components are carefully chosen to align with the four key components of economic infrastructure used by the AfDB in the computation of the Africa Infrastructure Development Index (AIDI), namely: WSS, electricity, Transportation, and ICT. 

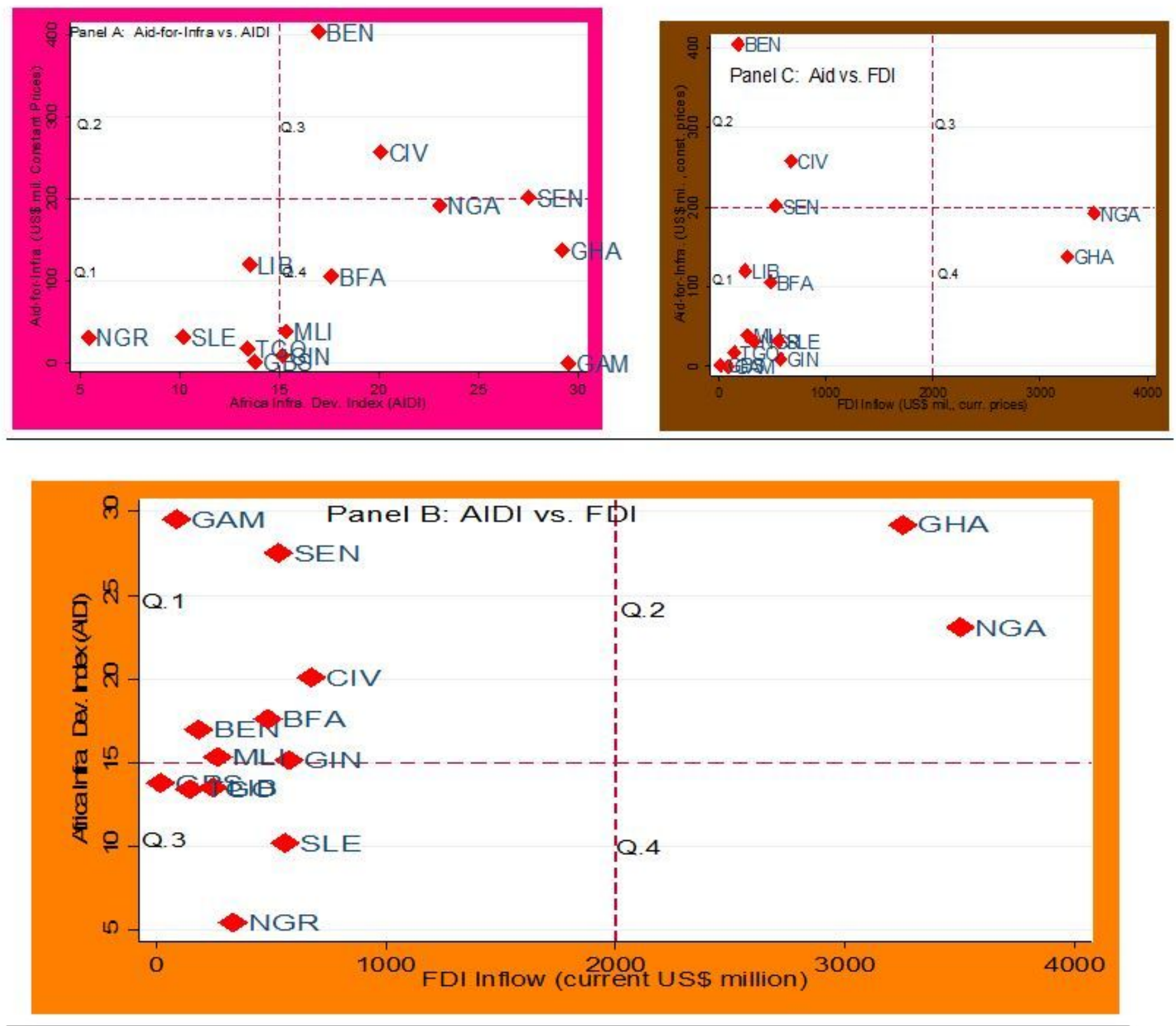

\section{Figure 2}

Cross-Sectional Scatter Chart of FDI, AIDI \& aid-for-Infrastructure (2017/2018) Note: (i) The reference lines (Horizontal and vertical) is based on the (estimated) median FDI and aid-for-infrastructure data for the period; (ii)Data for both FDI inflow (UNCTAD) and aid-for-infrastructure (OECD-DAC CRS) stops at 2017; (iii) Panel $A$ is closely related to objective 1 because it shows the link between aid and infrastructure. Panel $C$ extends the link to FDI while panel B look at the channel (infrastructure channel) and links infrastructure to FDI; (iv) Data for AIDI (AfDB, 2019) include 2018 figures) and so we use the average AIDI for 2017 and 2018. 

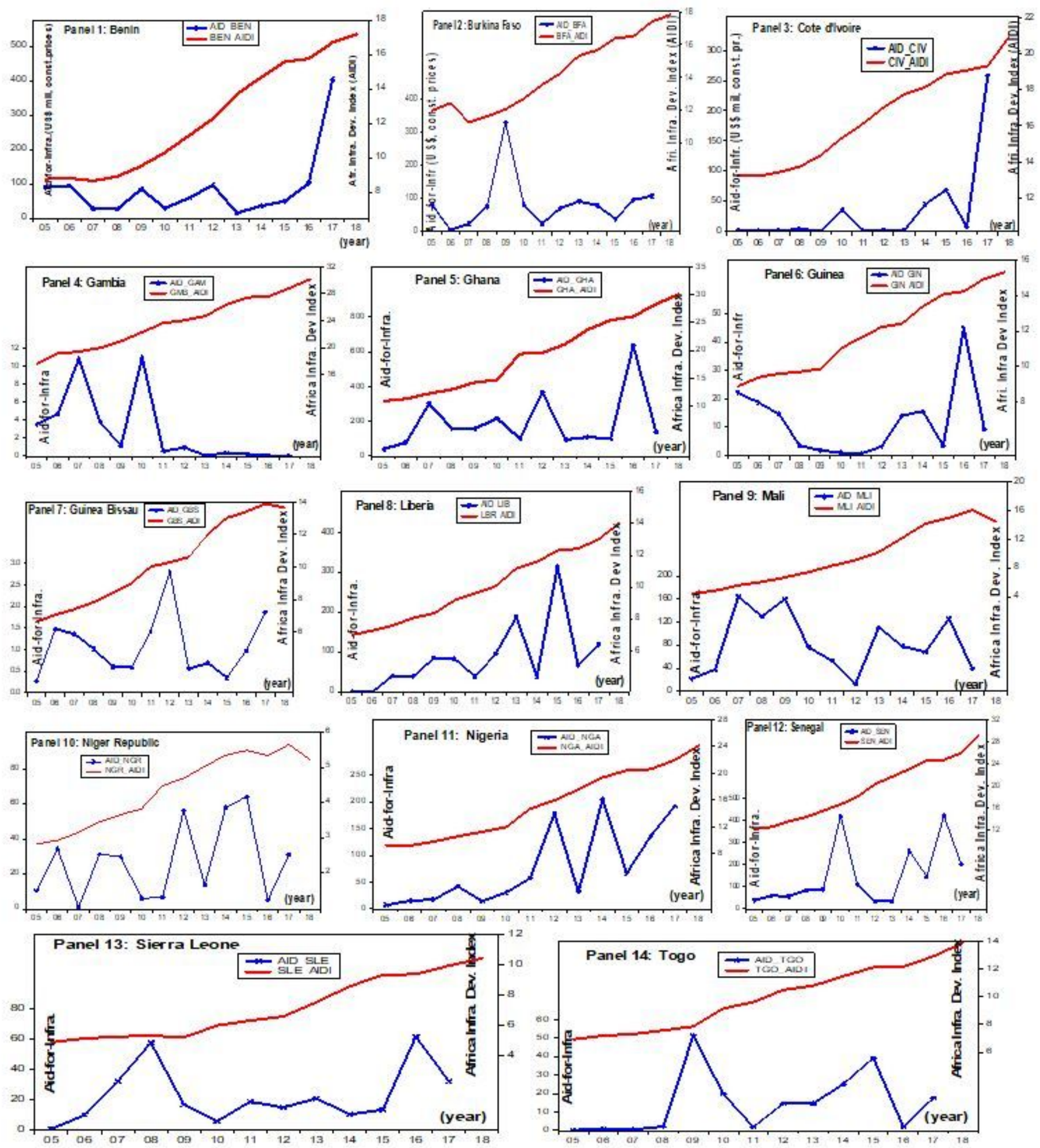

\section{Figure 3}

Trend Characterization of Model Variables (Super-imposed) Figure 3 shows the graph of aid-forinfrastructure commitments (US\$ million, constant prices) scaled on the left vertical axes superimposed on the graph of infrastructure outcome, AIDI (measured from 0 -100) which is scaled on the right vertical axis. Our motivation for super-imposing the two variables is with a view to understanding more clearly the evolution of aid-for-infrastructure vis-à-vis infrastructure outcome (AIDI). Note: (i) AIDI has a value from 0 
to 100 with higher score presenting higher infrastructure endowment or outcome. However, AIDI scores for developing ECOWAS countries are generally low; it ranged from $5 \%$ to $29.5 \%$ for our sample; (ii) Aid_Ben represents 'aid-for-infrastructure' to Benin while BEN_AIDI represents infrastructure index for Benin. For our sample, aid data ranged from \$0.3 US million to \$395 US million; (iii) The blue line (annotated with spikes) represents aid-for infrastructure and is scaled on the left vertical axis while the red line represents infrastructure endowment/outcome (AIDI) which is scaled on the right vertical axis of each panel.

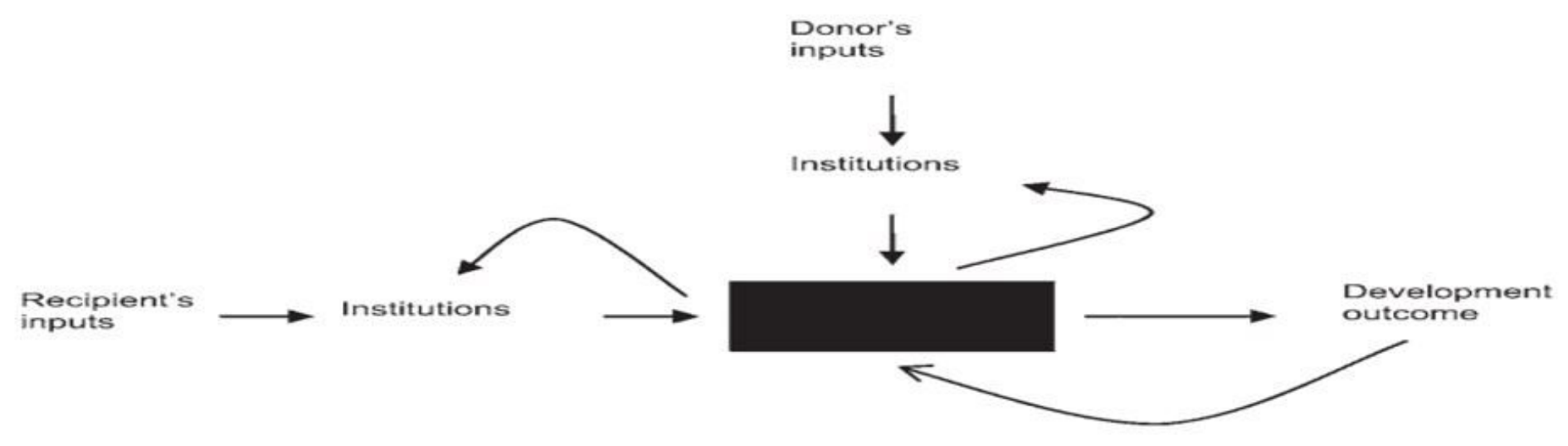

Figure 4

Aid Effectiveness, Transmission Channels, and the Black Box Source: Adapted from Jerve, Shimomura and Skovsted Hansen (2008:11)

\section{Supplementary Files}

This is a list of supplementary files associated with this preprint. Click to download.

- AppendixARESULTS.docx 